\title{
NILAI NILAI ISLAM PADA WAYANG KULIT, MENJADIKAN PERAN PENTING DALAM PERKEMBANGAN SENI ISLAMI DI INDONESIA
}

\author{
Otok Herum Marwoto *)
}

\begin{abstract}
One of the many works of art heritage in Indonesia is a shadow puppet performance (Wayang Kulit). Wayang Kulit is a one of branch of art that is popular and favored by some Indonesian, a work of art that is considering masterpiece based onphilosophical value contained in its story.

Through the characters and the story, wayang has a role in building nation character. Since wayang is one of Indonesian valuable art tradition, if should be maintained and preserved in order to build and empower nation's identity. The philosophy values in wayang always incourage people to do a good spare not a harmful things, the spirit of commanding tho good and fortidding unjust or a tern in the shadow puppet is "Memayu Hayuning Bebrayan Agung", according to their own beliefs and religion.

Islam as a religion that full of value and norm has its own rule for its follower. If thr follower willing to obey the rule then he or she will get happines in the world and here after. Related to this effort, art is fully needed in the knowledge transfoemation process and valuable Islamic Education.
\end{abstract}

Keyword: leather puppet, Art and Islam

\begin{abstract}
ABSTRAK
Salah satu dari banyak karya seni warisan di Indonesia adalah kinerja wayang kulit (Wayang Kulit). Wayang Kulit adalah salah satu cabang seni yang populer dan disukai oleh beberapa Indonesia, sebuah karya seni yang sedang mempertimbangkan nilai onphilosophical berbasis karya yang terkandung dalam cerita tersebut.

Melalui karakter dan cerita, wayang memiliki peran dalam membangun karakter bangsa. Karena wayang merupakan salah satu seni tradisi yang berharga Indonesia, jika harus dijaga dan dilestarikan dalam rangka membangun dan memberdayakan identitas bangsa. Nilainilai filsafat wayang selalu incourage orang untuk melakukan cadangan yang baik bukan hal yang berbahaya, semangat memerintah tho baik dan fortidding tidak adil atau tern di wayang kulit adalah "Memayu Hayuning Bebrayan Agung", menurut keyakinan dan agama mereka sendiri.
\end{abstract}

\footnotetext{
* Otok Herum Marwoto (otok_hm@gmail.com), Mahasiswa Program Penciptaan dan Pengkajian Seni Pascasarjana Institut Seni Indonesia Yogyakarta
} 
Islam sebagai agama yang penuh nilai dan norma memiliki aturan sendiri untuk pengikutnya. Jika thr pengikut bersedia untuk mematuhi aturan maka ia akan mendapatkan kebahagiaan di dunia dan di sini setelah. Terkait dengan upaya ini, seni sepenuhnya diperlukan dalam proses transfoemation pengetahuan dan Pendidikan Islam berharga.

Kata kunci: wayang kulit, Seni dan Islam

\section{PENDAHULUAN}

\section{Wayang Kulit sebagai Media Penyebaran Islam}

Salah satu dari sekian banyak hasil kesenian warisan nenek moyang bangsa Indonesia adalah wayang kulit. Wayang kulit merupakan cabang kesenian yang populer dan digemari oleh sebagian masyarakat Indonesia, suatu karya seni yang diakui adhiluhung, terutama nilai filsafat yang terkandung dalam cerita wayangnya. Wayang kulit purwa diakui sebagai suatu hasil karya seni yang tinggi bahkan telah mencapai puncak keindahannya, akan tetapi bentuk dari wayang kulit purwa itu sendiri sampai kini masih terus berkembang, walaupun dalam kadar yang rendah (perubahan yang tidak begitu menyolok). Kata wayang (bahasa Jawa), bervariasi dengan kata bayang, yang berarti bayang-bayang atau bayangan. Wayang waktu itu berarti mempertunjukkan bayangan yang selanjutnya menjadi seni pentas bayangbayang atau wayang. (Sri Mulyono, 1983. Simbolisme dan Mistisisme dalam Wayang. Jakarata: Gunung Agung, hal. 51)

Wayang kulit sebagai boneka dua matra memiliki perbedaan karakteristik yang cukup menonjol dengan bentuk boneka wayang lain. Wayang kulit menampilkan distorsi perwujudan bentuk yang memiliki keistimewaan tertentu. Bentuk rupa dengan ketepatan distorsinya mampu mencerminkan beragam watak manusia. Tak heran wayang kulit mampu berevolusi selama beratus-ratus tahun untuk mencapai bentuk yang paling mantap. ${ }^{1} \quad$ (Sutopo, H.B.,Wayang Kulit Bahasa Metaforik Yang Kaya Makna, Seni: Jurnal Pengetahuan dan Penciptaan Seni, II/02 April 1992, BP ISI Yogyakarta, 1992, hal. 69)

Masyarakat Jawa memiliki kecenderungan untuk menyampaikan sesuatu secara tidak langsung yaitu melalui simbol, sanepan (perumpamaan), ataupun sindiran. Gaya bahasa semacam itu sangat mengakar di dalam kehidupan masyarakat, sehingga banyak diketahui aturan tidak tertulis. Hal tersebut sangat menarik untuk dikaji dalam mencari suatu kebenaran. Metode komunikasi tersebut dapat menyampaikan pesan ataupun ajaran dengan baik tanpa menimbulkan konflik antar komunikan.

Wayang kulit sebagai salah satu dari berbagai akar budaya seni tradisional Indonesia, pada masa lampau, terutama di Jawa, ikut berperan penting terhadap perkembangan agama Islam di negeri ini. Agama Islam berkembang ke berbagai pelosok dunia termasuk di Indonesia. 
Kedatangan agama Islam ke negeri ini telah melewati beberapa negara di dunia sudah barang tentu memiliki adat, kebiasaan dan kebudayaan sendiri yang sedikit banyak telah memengaruhi perkembangan agama Islam yang masuk ke Indonesia. Sehingga telah mengalami penyesuaianpenyesuaian, termasuk penyebaran melalui seni tradisional wayang kulit. Oleh mereka kesenian Jawa berkembang hingga mencapai puncaknya yang kemudian dikenal dengan seni klasik. Salah satu kesenian yang hinga kini tetap populer adalah wayang kulit purwa. Wayang kulit merupakan produk budaya yang dihasilkan jauh sebelum agama Islam masuk di Indonesia yang keberadaannya masih dipertahankan. Namun dalam kelangsungannya wayang kulit ini mengalami perubahan drastis baik menyangkut bentuk maupun pemaknaannya.

Wayang kulit purwa yang telah menemukan bentuknya pada masa Hindu di Jawa, di masa Islam ini mengalami perubahan di segala bidang dari tampilan wujud maupun fungsi disesuaikan dengan ajaran-ajaran dan aturan dalam agama Islam.

Memasuki masa Islam di Indonesia, wayang kulit purwa berkembang pesat setelah terjadi akulturasi antara budaya lama dengan budaya baru yaitu ajaran Islam, sehingga wujud wayang kulit menjadi suatu karya seni yang tinggi nilainya

Pada masa Islam ini ditegaskan bahwa penggunaan kulit sebagai bahan baku wayang yang sebelumnya belum disebutkan secara jelas, tetapi pada masa ini digunakan kulit binatang kerbau.
Stilasi bentuk wayang kulit purwa sudah sangat jauh dari sumbernya, namun demikian bentuk wayang kulit masih dapat dikenali bagian-bagiannya. Bentuk wayang kulit purwa yang telah digayakan sedemikian jauh itu membuat sangat berbeda dengan wujud manusia.

Wayang kulit dalam bentuk aslinya dipergunakan untuk upacara agama. Pada abad ke-11 sudah mulai populer di kalangan rakyat. Sejak tahun 1058, bahkan sejak tahun 778 atau lebih tua lagi, sudah ada wayang atau ringgit. Angka tahun 1058 disalin oleh Brandes berdasarkan angka tahun dalam prasasti di Bali yang memberikan bukti adanya pertunjukan wayang. (Sri Mulyono, 1983. Simbolisme dan Mistisisme dalam Wayang. Jakarata: Gunung Agung, hal. 22-23)

Pada periode penyebaran agama Islam di Jawa, para muballigh (wali songo) dalam menjalankan dakwah Islam telah memakai alat berupa wayang kulit. Salah seorang wali songo yang piawai memainkan wayang kulit sebagai media penyebaran Islam adalah Sunan Kalijaga. Mengingat cerita itu sarat dengan unsur Hindu-Budha, maka Sunan Kalijaga berusaha memasukkan unsur-unsur Islam dalam pewayangan. Ajaran-ajaran dan jiwa kelslaman itu dimasukkan sedikit demi sedikit. Bahkan lakon atau kisah dalam pewayangan tetap mengambil cerita Pandawa dan Kurawa yang mengandung ajaran kebaikan dan keburukan.

Gaya penggambaran wayang kulit purwa yang demikian itu merupakan pilihan para ahli pada saat itu dan merupakan akibat dari langkanya penggambaran secara realistik. Hal ini ditempuh agar wayang kulit purwa 
dapat tampil dengan baik dan tidak melanggar larangan menurut ajaran agama Islam, dengan demikian wayang kulit purwa sudah dapat diterima dalam agama Islam, karena tidak lagi menggambarkan manusia atau binatang secara realistis. Kenyataannya wujud wayang kulit purwa sudah berbeda jauh dengan gambaran manusia, walau wayang kulit memiliki mata, hidung, dan mulut orang. Kondisi inilah yang mendorong para muballigh merombak bentuk wayang kulit dan memasukkan unsur baru berupa ajaran Islam dengan membuat "Pakem Pewayangan Baru"nsur baru berupa ajaran Islam dengan membuat "Pakem Pewayangan Baru" yang bernafaskan Islam, seperti cerita Jimat Kalimasodo, atau dengan cara menyelipkan ajaran Islam dalam pakem pewayangan yang asli. Dengan demikian masyarakat yang menonton wayang dapat menerima langsung ajaran Islam dengan sukarela dan mudah. (K. Ismunandar, 1988. Wayang Asal-usul dan Jenisnya. Semarang: Dahara Prize, hal. 97)

Dalang sebagai juru dakwah harus mampu melaksanakan tugasnya dalam memberi penerangan agama. Untuk melaksanakan tujuan dakwah melalui pewayangan dan agar mudah diterima oleh masyarakat, maka para muballigh menggunakan simbol atau filsafat.

Wayang kulit penuh dengan simbolik. Dalam pertunjukannya menggambarkan perjalanan hidup manusia, yakni manusia yang mencari keinsyafan akan sangkanparannya, bukan manusia yang hanya hidup dan tidak mati. (Solichin Salam, 1960. Sekitar Wali Sanga. Jakarta: Menara Kudus, hal. 65).
Gambaran yang jelas dapat dilihat dari struktur lakon yang dibawakan oleh dalang yakni menceriterakan perjalanan hidup salah satu tokoh pewayangan. Pada cerita "Jimat Kalimosodo", bahwa Jimat Kalimosodo adalah senjata ampuh milik Prabu Darmokusumo (Yudistira). Dalam cerita dilukiskan Puntadewa sebagai seorang raja yang berbudi pekerti luhur sebagai manifestasi kalimat syahadat yang selamanya mengilhami kearifan dan keadilan. Jimat ini dimiliki oleh keluarga yang baik, seperti keluarga Pandawa. Istilah Pandawa Lima sering diartikan sebagai rukun Islam yang lima.

Salah satu perlengkapan wayang yang disebut Gunungan atau Kayon memiliki makna simbolis. Kayon menyerupai bentuk masjid, apabila dibalik akan menyerupai jantung manusia. Hal ini mengandung falsafah bahwa dalam kehidupan umat Islam, jantung hatinya harus senantiasa berada di masjid. Kreativitas para wali memanfaatkan budaya setempat sebagai media penyebaran Islam yang efektif tersebut, telah mempercepat pertumbuhan dan perkembangan Islam di Jawa. Selain itu para wali juga berjasa dalam mempopulerkan seni wayang sebagai bentuk kesenian pentas yang merupakan salah satu kekayaan budaya Indonesia yang telah berakar jauh ke masa lalu dan cukup banyak mengalami pertumbuhan dan penyempurnaan dari masa ke masa.

Budaya keislaman dalam wayang kulit purwa tidak saja dijumpai pada wujudnya saja, tetapi ditemukan pula pada istilah-istilah dalam bahasa padhalangan, bahasa wayang, nama tokoh wayang, dan lakon (cerita) yang dipergelarkan. 
Satu hal yang sangat menonjol dalam pengambaran wayang kulit terlihat pada penggambaran tokoh Bathara Guru salah satu tokoh dewa yang bertangan empat, masih mengacu pada penggambaran tokoh dari masa-masa hindu yang terdapat pada relief candi.

Wayang kulit purwa yang diwujudkan dalam masa Islam di Indonesia ini berkembang di daerah Jawa Tengah dan Jawa Timur termasuk Madura, dan Yogyakarta, serta daerah lain yang mendapat pengaruh agama Islam. Jenis wayang kulit purwa ini tetap lestari hidup hingga sekarang dan menjadi sumber ide dalam penciptaan bentuk wayang kulit baru yang sesuai dengan jiwa sekarang dan perkembangan jaman. Berbagai bentuk wayang kulit kreasi yg bernuansa Islami banyak berkembang di Indonesia, yang semua itu mempunyai tujuan yang sama yaitu dalam rangka memajukan pendidikan seni Islami sebagai sarana dakwah kultural.

Contoh bentuk wayang kulit kreasi bernuansa Islami

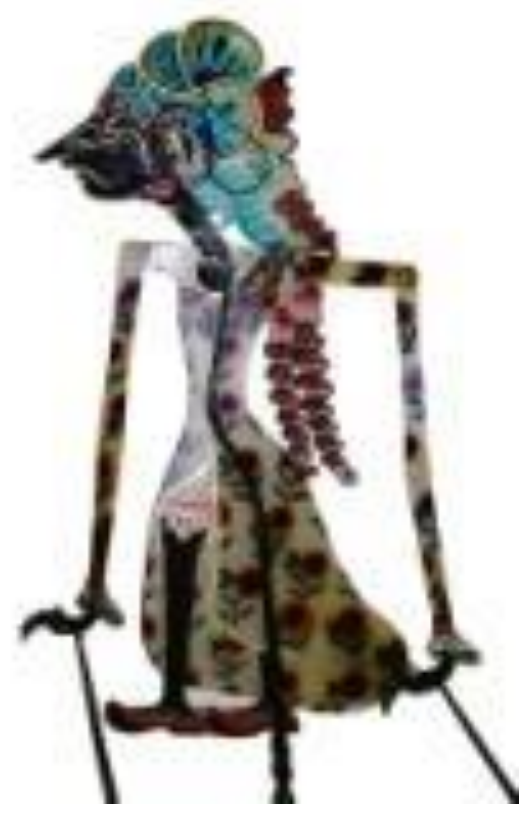

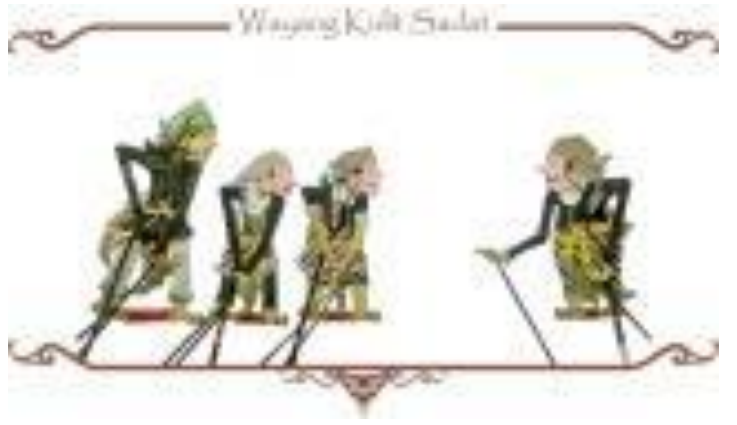

Wayang Kreasi karya: Otok HM. (2005) Wayang Sadat karya: Suryadi Warnosuardjo (1985)

\section{Pendidikan Seni Dalam Islam}

Pendidikan adalah sebuah usaha yang terencana dan sistematis dalam rangka berupaya untuk membentuk kedewasaan pribadi yang mandiri, tangguh dan siap untuk menghadapi segala bentuk tantangan di masa yang akan datang. Pendidikan pada hakikatnya merupakan kebutuhan setiap individu dalam mengembangkan dan mengarahkan kehidupannya di masa yang akan datang.

Pendidikan merupakan kebutuhan setiap individu manusia. Dengan pendidikan manusia mampu menghadapi segala tantangan yang ada untuk mencapai tujuan hidup yang diinginkan. Sercara Etimologi pendidikan dalam perspektif Islam diidentikkan dengan attarbiyah yang berasal dari tiga akar kata yaitu; 1) raba berarti beratambah dan tmbuh; 2) rabiya yarba yang berarti menjadi besar; 3) rabba yarubbu yang berarti memperbaiki, menguasai urusan, menuntun, menjaga dan memelihara.

At Tarbiyah secara etimologi juga identik dengan kata rabbani. Dalam Al Qur,an 3: 79 dan 146 disebutkan kata rabbaniyah (bentuk jama' deari kata rabbani) yang memiliki makna orang-orang yang sempurna ilmu dan taqwanya kepada Allah SWT. Nabi Muhammad SAW 
memebrikan makna pendidikan (At Tarbiyah) dengan istilah rabbaniyin dan rabbani seperti berikut.

"Jadikanlah kamu para pendidik yang penyantun, ahli fiqih dan berilmu pengetahuan. Dan dikatakan pendidik "rabbani" apabila seseorang telah mendidik manusia dengan ilmu pengetahuan, dari sekecil-kecilnya sampai pada yang lebih tinggi"

Dari pemaparan diaatas kata alrabbani diidentikkan dengan at-tarbiyah, yang berarti proses transformasi ilmu pengetahuan yang dilakukan secara bertahap. Proses tersebut dilakukan dengan proses pengenalan, hafalan dan ingatan yang belum menjangkau proses pemahaaman dan penalaran.

Sebaliknya bila, pengertian at tarbiyah disepadankan dengan rabbaniyin dan rabbaniyun sebagaimana dalam AlQur'an 3:79 dan 146 tersebut, maka makna at tarbiyah adalah proses transformasi ilmu penegtahuan dan sikap pada anak didik, yang memepunyai semangat tinggi dalam memahami dan menyadari kehidupannya sehingga terwujud ketaqwaan, budi pekerti dan pribadi ayng luhur.

Secara terminologi at tarbiyah menurut Al-Ghalayani adalah upaya penanaman etika yang mulia pada jiwa anak yang sedang tumbuh dengan cara memberi petunjuk dan nasehat, sehingga ia memiliki potensi-potensi dan kompetensi-kompetensi jiwa yang mantab yang dapat membuahkan sifat-sifat bijak, baik, cinta akan kreasi, dan berguna bagi tanah airnya. Kata At tarbiyah yang mempunyai arti pendidikan diartikan dengan usaha sadar dan terencana untuk mewujudkan sarana belajar dan proses pembelajaran agar peserta didik secara aktif mengembangkan potensi dirinya untuk memiliki kekuatan spiritual keagamaan, penegndalian diri, kepribadian yang diperlukan dirinya, masyarakat, bangsa dan negara.

Apabila kedua pemahaman pendidikan diatas disinergikan maka pendidikan merupakan upaya yang dialkukan secara bertahap dan sistematis dalam rangka menanamkan nilai-niali luhur dalam diri peserta didik sehingga peserta didik memiliki sifat-sifat terpuji, memiliki kepribadian, kecerdasan, ketrampilan dan mampu mengendalikan dirinya sehingga menjadi orang yang berguna bagi masyarakat, bangsa dan negaranya.

Seni merupakan kegiatan manusia yang amat menyenangkan karena didalamnya terdapat kegiatan bermain dan bereksplorasi serta bereksperimentasi dengan menggunakan unsur seni untuk mencipta suatu hal baru bagi diri mereka.

Menurut kamus besar Bahasa Indonesia seni adalah: 1) keahlian membuat karya yang bermutu (dilihat dari segi kehalusannya, keindahannya, dsb); 2) karya yang diciptakan dengan keahlian yang luar biasa, seperti tari, lukisan, ukiran. Sedangkan dalam kamus ilmiah populer seni diartikan sebagai segala yang berkaitan dengan karya cipta yang dihasilkan oleh unsur rasa. Seni merupakan ungkapan halus dari perasaan yang mendalam yang dilahirkan dalam sebuah karya cipta. Karya ini bisa berupa sebuah bahasa, gerak teaterikal, olah suara dan lain sebagainya. Dari pengertian diatas tampak bahwa seni merupakan eksplorasi dan implementasi dari rasa yang halus dan mendalam dalam diri manusia. 


\section{Pendidikan Seni Islami di Indonesia}

Sebagaimana telah di bahas diatas bahwa pendidikan memiliki beberapa pengertian sebagai yang telah disampaikan para pakar serta ahli di bidangnya. Secara garis besar pendidikan merupakan upaya yang dilakukan dalam rangka menanamkan niali-nilai luhur pada diri peserta didik sehingga pada saatnya nanti, peserta didik siap dan mampu membentengi diri dari pengaruh-pengaruh negatif dari luar sekaligus mampu dalam mengembangkan segala potensi yang ada pada dirinya untuk menjawab berbagai tantangan yang muncul di dalam kehidupannya.

Salah satu upaya yang perlu diperhatikan dan menjadi sorotan adalah upaya transformasi ilmu dan penanaman nilai-nilai luhur dalam diri peserta didik. Upaya bukanlah sebuah hal yang mudah. Karena membutuhkan perhatian serius agar bisa tercapai secara maksimal. Salah satu cara dalam usaha transformasi ilmu dan nilai-nilai luhur itu adalah melalui media seni.

Meurut Cut Kamaril Wardani, seni memiliki sifat multidimensional, multilingual dan multikultural yang memuliki potensi dalam pengembangan kecerdasan manusia agar mampu bertahan hidup dan mampu tampil secara bermartabat pada masa kini dan masa depan.

Menurut V, Lowenfield sebagaimana dikutip oleh Cut Kamaril wardani, melalui sifat multidimensional yang dimiliki seni, pada dasarnya kemampuan dasar manusia yang meliputi fisik, perceptual intelektual, emosional, sosial, kreatifitas dan astetik dapat dikembangkan. Dengan sifat seni yang multidimensional seorang akan mampu mengembangkan danmenggali potebsi yang berbeda dalam dirinya serta mampu mengungkapkannya dalam bentuk kreatifitas yang mengandung nilai-nilai estetik.

Sedangkan sifat multilingual yang dimiliki seni memungkinkan manusia mampu mengembangkan kemampuannya dalam berkomunikasi melalui beragam bahasa disamping bahasa verbal. Bahasa yang dimaksud disini adalah bahas bahasa untuk berekspresi dan berkomunikasi secara rupa, bunyi, gerak dan keterpaduannya.

Seni merupakan bahasa, rasa citra atau image bagi manusia. Oleh karena itu seni dinyatakan sebagai cermin kehidupan atau cermin realita. Cerminan ini akan tampak pada setiap laku dan pola interaksi yang tampak dalam realita kehidupanseseorang.

Sifat Multikultural seni dapat dijadikan dasar pemersatu bangsa dengan mengembangkan kemampuan manusia untuk saling menghargai akan adanya perbedaan. Pemahaman terhadap keanekaragaman budaya yang dimiliki merupakan sebuah landasan yang kuat dalam mempersatukan perbedaan menjadi kesatuan yang utuh. Akan ntetapi ketidakpahaman terhadap keanekaragaman yang dimiliki merupakan akar perpecahan dan permusuhan.

Dengan demikian seni dengan berbagai sifat yangdimiliki memiliki arti dan peran penting dalam pendidikan. Seni merupakan media dalam menanamkan nilai-nilai luhur yang terkandung misi pendidikan. Seni juga merupakan sarana 
yang tepat dalam rangka transformasi ilmu pengetahuan pada diri seorang murid.

Pada kenyataannya pendidikan yang diselenggarakan oleh Pemerintah Indonesia dapat kita kelompokkan menjadi 2 macam, yaitu Pendidikan Umum dan Pendidikan Agama. Di kotomi dalam pendidikan ini muncul sebagai sebuah akibat dari adanya kronologis sejarah Indonesia yang kala itu di jajah oleh Belanda. Warisan itu masih tetap berlaku sampai masa sekarang. Dalam pembahasan ini transformasi dan internalisasi pendidikan melalui seni lebih difokuskan pada pendidikan Islam.

Pendidikan Islam berbeda dengan Pendidikan Agama Islam. Muhaimin menyebutkan bahwa Pendidikan Agam Islam adalah pendidikan yang materinya hanya sebatas mengajarkan ajaran agama Islam saja. Sedangkan Pendidikan Islam adalah nama sistem, yaitu sistem pendidikan yang Islami, yang memiliki komponen-komponen yang secara keseluruhan mendukung terwujudnya sosok muslim yang di edialkan. Jadi pendidikan Islam tidak hanya mengajarkan ajaran-ajaran agama an sich saja, namun juga mengjarkan berbagai keilmuan dimana reori-teorinya berlandaskan pada Al-Qur'an dan Al Haists.

Islam sebagai agama syarat dengan nilai-nilai serta norma-norma yang mengikat didalammya, Islam memiliki aturan tersendiri bagi umatnya yang apabila umat mau dan patuh melaksanakannya, maka ia akan mendapatkan kebahagiaan di dunia dan akhirat. Dalam upaya inilah seni diperlukan dalam proses transformasi ilmu serta nilainilai luhur Pendidikan Islam.

\section{Nilai-nilai Pendidikan yang terkandung Dalam Budaya Wayang}

Lewat pertunjukkan wayang melalui tokoh serta ceritanya mempunyai peran dalam pembinaan dan pendidikan untuk membangun karakter bangsa. Karena wayang menjadi salah satu kekayaan tradisi bangsa Indonesia, sudah seharusnya dilestarikan dan dimanfaatkan dalam pembentukan budaya bangsa yang akan jadi potret orang Indonesia sampai kapanpun.

Nilai-nilai filosofi yang terkandung dalam pewayangan selalu mengajak masyarakat untuk berbuat baik dan menghindari kejahatan, serta menanamkan kepada masyarakat semangat "amar ma'ruf nahi mungkar" atau istilah dalam pewayangan "memayu hayuning bebrayan agung", sesuai dengan ajaran agama dan kepercayaan masingmasing.

Dalam kisah pewayangan ini yang patut diteladani adalah peran tokoh Sri Rama dan Arjuna yang memilki sifat selalu mengedepankan kebenaran dan keadilan, dalam penampilanya rapi, penuh dengan senyum, tutur bahasanya halus, tingkah lakunya terukur dan tampak tidak berminat membuat orang susah terhadap siapapun.

Peran kepemimpinan tokoh Abiasa yang juga patut diteladani, karena paada waktu ia menjadi penguasa di negeri Astina selalu mencintai dan memberi perhatian kepada rakyatnya, memiliki kepribadian yang kuat dan konsisten, memiliki visioner dan integritas yang tinggi, sehingga ia dicintai dan dipercaya oleh pengikutnya. Dalam menjalankan kepemimpinan hendaknya berlandaskan pada 
kepemimpinan "Hasta Brata" yang terdapat 8 (delapan) laku nilai-nilai watak kepemimpinan yang meniru sifat-sifat keutamaan alam semesta, yaitu: (1) Bumi yaitu seorang pemimpin harus setia memberi kebutuhan-kebutuhan hidup kepada siapa saja, sabar(bumi sebagai sumber kehidupan); (2) Air yaitu pemimpin harus selalu turun ke bawah(rakyat) untuk melihat dan memberi kesejukan serta tidak menempatkan diri lebih tinggi dan lebih rendah daripada siapapun,karena air bertabiat rata; (3) Angin yaitu pemimpin harus sanggup menghembus siapa saja tanpa pandang bulu dan tanpa pilih kasih; (4) Bulan yaitu pemimpin harus dapat menerangi siapapun yang sedang kegelapan sehingga dapat memberikan kesejahteraan,keindahan dan harapan; (5) Matahari yaitu pemimpin harus memberi petunjuk sebagai sumber kekuatan yang menghidupkan; (6) Samudra yaitu pemimpin harus memberi kasih sayang dan kebebasan tak terbatas, karena samudra luas dan tak bertepi: (7) Gunung yaitu pemimpin harus kukuh dan kuat untuk melindungi rakyatnya; (8) Api yaitu pemimpin harus mampu membakar dan memberi kehangatan (mampu memberantas kejahatan dan memberi kenikmatan).

Dengan harapan muatan tulisan diatas,dapat menyadarkan masyarakat akan pentingnya kearifan nilai-nilai budaya lokal dalam membangun sosok watak bangsa yang memiliki budaya unggul, baik keunggulan bidang spiritulitas, intelektualitas, disiplin dan ethos kerja, yang selanjutnya diharapkan dapat mendorong terwujudnya cita-cita reformasi untuk memenuhi harapan kita Dalam dunia pewayangan kita juga mengenal beberapa hal diantaranya kata brahmana, ksatria, wisya, sudra. Dengan mengenal tingkat status sosial maka masing-masing tokoh bisa mengenal dirinya sebagai apa dan harus bagaimana dalam bersikap dan bertindak dalam kehidupan sehari-hari dalam dunia pewayangan. Misal Seorang Brahmana dalam membawakan diri harus: Sumeh (ramah tamah terhadap siapapun dan selalu bermuka jernih. Murah senyum), Sareh (tidak mudah emosi, semua diatasi dengan kebijaksanaan), Waleh (selalu berterus terang dan tidak ada yang dirahasiakan), Sumeleh (percaya kepada keadilan Tuhan. Berpegang pada siapa yang menanam dia yang akan menuai), Aja remeh (tahu untuk tidak bertindak nistha, seperti menipu, maling, membunuh, main perempuan dan lainlain).

Kastra Sudra dalam dunia pewayangan menggambarkan kawula alit yang penuh dengan kekurangan baik secara fisik maupun mental spiritual, sehingga mereka digambarkan dalam bentuk yang tidak sempurna. Misal seperti tokoh dibawah ini. Nala Gareng, secara fisik dia diberi kekurangan: mata kero, sikil pencik, tangan ceko, irung menthol. Petruk (wudel bodhong, irung bangir, awak bungkuk), Bagong (pawakan cebol, lambe doble, irung pesek), Semar (secara fisik sama dengan Bagong), Bilung (orang kerdil, banyak borok, kudisan), Togog juga demikian adanya, semuanya ini menggambarkan kawula alit yang penuh dengan kemiskinan, kebodohan, keterbelakangan. Tokoh-tokoh inilah yang 
dapat melengkapi dunia pertunjukan wayang kulit sehingga semakin komplit dan dapat diterima disemua kalangan masyarakat. Dengan tokoh2 sudra inilah para dalang mampu memberikan kritikkritik yang pedas terhadap tatanan masyarakat dan pemerintahan yang tidak sesuai dengan norma.

\section{KEPUSTAKAAN}

Amir,Hazim, Nilai-nilai Etis dalam Wayang, Sinar Harapan, Jakarta, 1997

Anderson, Benedict R.O.G., Mithology and the Tolerance of the Javanesse, Cornell University, Ithaca, New York, 1965

Cassirer, Ernst, Manusia dan Kebudayaan, Sebuah Essei Tentang Manusia, terjemahan Alois A. Nugroho, PT Gramedia, Jakarta, 1987

Holt, Claire, Art in Indonesia, Cornell University Press, Itaca, New York, 1967

Kempers, Bernet, , AJ, Ancient Indonesian Art, Harvard University Press, Cambridge, Massachusetts, 1959

K. Ismunandar, Wayang Asal-usul dan Jenisnya. Semarang: Dahara Prize, 1988

Mulyono, Sri, Simbolisme Mistikisme dalam Wayang, Penerbit PT Gunung Agung, Jakarta 1979
Nawawi, Hadari, Metode Penelitian Bidang Sosial, Gadjah Mada University Press, Yogyakarta, 1990

Rahman,Aris. 2008. http://www.madinask.com. [19 Maret 2009]

Sagio dan Samsugi, Wayang Kulit Gagrag Yogyakarta. Morfologi, Tatahan, Sunggingan dan Teknik Pembuatannya, Haji Masagung, Jakarta, 1991.

Soedarso Sp., M.A., Morfologi Wayang Kulit (Wayang Kulit dipandang dari Jurusan Bentuk), dalam pidato ilmiah pada Dies Natalis Institut Seni Indonesia Yogyakarta Ketiga, Yogyakarta, 1987

Soekatno, Mengenal Wayang Kulit Purwa. Klasifikasi, Jenis dan Sejarah, Aneka Ilmu, Semarang, 1992.

Solichin Salam, Sekitar Wali Sanga. Jakarta: Menara Kudus, 1960

Sri Mulyono, Simbolisme dan Mistisisme dalam Wayang. Jakarata: Gunung Agung, 1983

Sudarjanto, Ajaran Moral Dalam Wayang. http://sudarjanto.multiply.com, 2008

Sukasman, Wayang Kulit Purwa Dilihat Dari Segi Seni Rupa, Departemen Pendidikan dan Kebudayaan Direktorat Jendral Kebudayaan Badan Penelitian dan Pengembangan Pendidikan dan 
Kebudayaan, Proyek Javanologi,

Yogyakarta, 5 Juni 1984

Sutopo, H.B.,Wayang Kulit Bahasa Metaforik Yang Kaya Makna, Seni: Jurnal Pengetahuan dan Penciptaan Seni, II/02 April 1992, BP ISI Yogyakarta, 1992, hal. 69 